\title{
Energy for a Sustainable Future
}

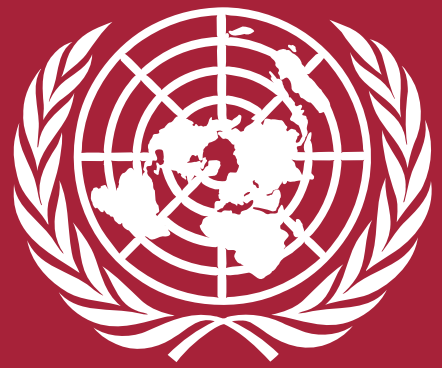

THE SECRETARY-GENERAL'S ADVISORY GROUP ON ENERGY AND CLIMATE CHANGE (AGECC)

SUMMARY REPORT AND RECOMMENDATIONS

28 April 2010

New York 


\section{CONTENTS}

FOREWORD BY THE SECRETARY-GENERAL

2

INTRODUCTION BY THE CHAIR.

3

ACKNOWLEDGEMENTS

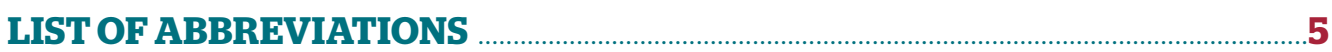

THE IMPORTANCE OF ENERGY

THE IMPERATIVE TO TRANSFORM NATIONAL ENERGY SYSTEMS ………...

TWO KEY GOALS

RECOMMENDED ACTIONS TO ACHIEVE THE ENERGY GOALS

ENERGY ACCESS AND ENERGY EFFICIENCY:

ANALYTICAL OVERVIEW

REFERENCES 


\section{FOREWORD BY THE SECRETARY-GENERAL}

This year, in September, world leaders will meet at the United Nations to assess progress on the Millennium Development Goals and to chart a course of action for the period leading up to the agreed MDG deadline of 2015. Later in the year, government delegations will gather in Mexico to continue the process of working towards a comprehensive, robust and ambitious climate change agreement. Energy lies at the heart of both of these efforts. The decisions we take today on how we produce, consume and distribute energy will profoundly influence our ability to eradicate poverty and respond effectively to climate change.

Addressing these challenges is beyond the reach of governments alone. It will take the active engagement of all sectors of society: the private sector; local communities and civil society; international organizations and the world of academia and research. To that end, in 2009 I established a high-level Advisory Group on Energy and Climate Change, chaired by Kandeh Yumkella, Director-General of the United Nations Industrial Development Organization (UNIDO). Comprising representatives from business, the United Nations system and research institutions, its mandate was to provide recommendations on energy issues in the context of climate change and sustainable development. The Group also examined the role the United Nations system could play in achieving internationally-agreed climate goals.

The Advisory Group has identified two priorities - improving energy access and strengthening energy efficiency - as key areas for enhanced effort and international cooperation. Expanding access to affordable, clean energy is critical for realizing the MDGs and enabling sustainable development across much of the globe. Improving energy efficiency is paramount if we are to reduce greenhouse gas emissions. It can also support market competitiveness and green innovation.

I commend the Group's recommendations to a wide global audience and look forward to their rapid implementation.

\section{Ban Ki-moon}

Secretary-General of the United Nations 


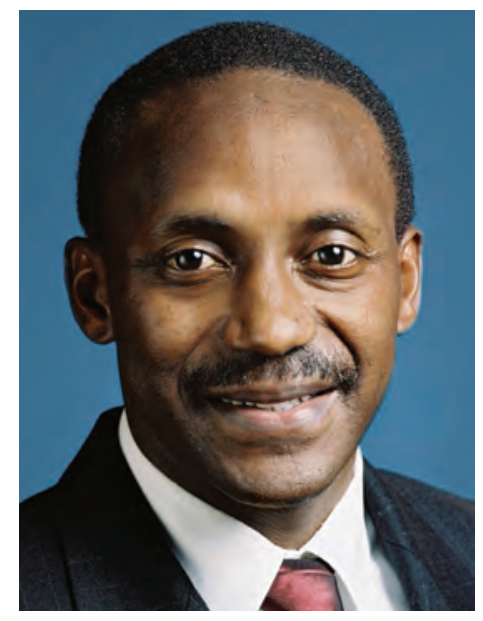

\section{INTRODUCTION BY THE CHAIR}

Energy is at the forefront of the global agenda. It is central to the issues of development, global security, environmental protection and achieving the MDGs. Profound changes are beginning to transform the way we supply, transform, deliver and use energy services - a trend that a revitalized global energy dialogue can reinforce, leading to a sustainable future for all with multiple co-benefits for development, human health, environment and climate change.

The United Nations system has responded to the challenges and opportunities in the energy system with numerous programmes and projects. The need for a strong and focused engagement is now clearer than ever before. Although there is no single United Nations entity with primary responsibility for energy, the establishment of UN-Energy as the interagency mechanism for coordination on these issues has allowed for a more focused system-wide approach.

The Secretary-General established the Advisory Group on Energy and Climate Change (AGECC) in June 2009 last year to advise him on the energy-related dimensions of the climate change negotiations. AGECC is a prime example of a multi-stakeholder partnership bringing together the UN system, including the World Bank, with the private sector and research institutions. Its work has benefited from a unique mix of policy orientation, technical expertise and business experience of leading figures in the field of energy. As chair of the Advisory Group, I deeply appreciate the enthusiastic participation and valuable contribution of all its members.

An important contribution of AGECC towards a sustainable energy future is this report. As the report makes clear, it is unacceptable that a third of humanity has no access to modern energy services and half of humanity has to rely on traditional biomass for meeting their basic needs. Eliminating energy poverty is of paramount importance in eradicating poverty. It is also essential to the achievement of the other Millennium Development Goals. At the same time, a vast potential for energy efficiency improvements across the energy supply and delivery chain remains largely untapped.

AGECC has therefore called for commitment and concerted action on two ambitious but achievable goals: universal access to modern energy services and improved energy efficiency. A global campaign can help raise awareness and galvanize countries and the international community into action. The United Nations system can catalyze this action by establishing a mechanism to track progress towards these goals and by providing the requisite support to strengthen national capacities to achieve them. Institutionally "embedding" the energy-related goals in the work of the United Nations system would help sustain efforts towards the achievement of the goals in the long term. UN-Energy is well positioned to be the hub for such collective engagement.

The Secretary-General has asked AGECC to continue its work and to put its collective weight behind the achievement of universal access to modern energy services and energy efficiency. In doing so, it will also contribute information and ideas to the work of the Secretary-General's High-Level Advisory Group on Climate Change Financing and the forthcoming High-Level Panel on Sustainable Development.

I continue to be energized by our collective endeavour under the leadership of the SecretaryGeneral, and the enormous opportunities for positive change that lie before us.

\section{Kandeh K. Yumkella Chair}




\section{ACKNOWLEDGEMENTS}

This report was prepared by the UN Secretary-General's Advisory Group on Energy and Climate Change (AGECC), which comprises of the following members:

- Kandeh K. Yumkella, Director General, UNIDO, Chair of UN-Energy and Chair of AGECC

- Tariq Banuri, Director, Division for Sustainable Development, UNDESA

- John Bryson, Former Chairman, Edison International, USA

- Suani Coelho, Coordinator, CENBIO-Brazilian Reference Center on Biomass, Brazil

- Yvo de Boer, Executive Secretary, UNFCCC

- José María Figueres, Former President of Costa Rica

- Carlos Slim Helú, Chairman, Fundación Carlos Slim, Mexico

- Dr. Sultan Ahmed Al Jaber, CEO, The Masdar Initiative, UAE

- Lars Josefsson, CEO, Vattenfall AB, Sweden

- Olav Kjørven, Assistant Administrator, UNDP, and Vice Chair, UN-Energy

- Sergey Koblov, Director, UNESCO Energy Centre, Russian Federation

- Helge Lund, CEO, Statoil, Norway

- Jacob Maroga, Former CEO, ESKOM, South Africa

- Alexander Mueller, Assistant Director-General, FAO

- Nebojsa Nakicenovic, Deputy Director, International Institute for Applied Systems Analysis, IIASA, Austria

- Jamal Saghir, Director, Energy, Water and Transport, The World Bank Group

- Shi Zhengrong, Chairman and CEO, Suntech Power Holdings, China

- Leena Srivastava, Executive Director, The Energy and Resources Institute, TERI, India

- Achim Steiner, Executive Director, UNEP

- Timothy Wirth, President, United Nations Foundation, USA

The AGECC would like to thank the many organizations and people who made important contributions to this report, through interviews, data and comments on various draft versions.

In particular, we would like to acknowledge a large volume of valuable feedback and inputs to the analysis presented in this report received from the Advisory Group members, and other reviewers and colleagues from ESKOM, IIASA, Statoil, Suntech Power, TERI, the United Nations Department for Economic and Social Affairs (UNDESA), the United Nations Development Programme (UNDP), the United Nations Environment Programme (UNEP), the United Nations Food and Agriculture Organization (FAO), the United Nations Foundation (UNF), the United Nations Framework Convention on Climate Change Secretariat (UNFCCC), the United Nations Industrial Development Organization (UNIDO), the United Nations Secretary-General's Climate Change Support Team (CCST), Vattenfall AB, and the World Bank

We would also like to thank McKinsey \& Company, who provided data and analytical support. 


\section{LIST OF ABBREVIATIONS}

\section{Acronyms}

\begin{tabular}{ll} 
ADB & Asian Development Bank \\
AGECC & Advisory Group on Energy and Climate Change \\
ASTAE & Asia Sustainable and Alternative Energy Program \\
Capex & Capital expenditure \\
CCS & Carbon capture and storage \\
CDM & Clean Development Mechanism \\
CFL & Compact fluorescent lamp \\
CIF & Climate Investment Funds \\
COP-15 & 15th Conference of the Parties \\
CTF & Clean Technology Fund \\
DTIE & Division of Technology, Industry and Economics \\
EGAT & Electricity Generating Authority of Thailand \\
ESMAP & Energy Sector Management Assistance Program \\
EUEI PDF & European Union Energy Initiative Partnership Dialogue Facility \\
FAO & United Nations Food and Agriculture Organization \\
GDP & Gross domestic product \\
GEF & Global Environment Facility \\
GHG & Greenhouse gas \\
GNESD & Global Network on Energy for Sustainable Development \\
GTZ & Gesellschaft für Technische Zusammenarbeit \\
IDA & International Development Association \\
IEA & International Energy Agency \\
IEEE & Institute of Electrical and Electronics Engineers \\
IPCC & Intergovernmental Panel on Climate Change \\
IRENA & International Renewable Energy Agency \\
ISO & International Organization for Standardization \\
LCGP & Low carbon growth plans \\
LED & Light emitting diode \\
LPG & Liquefied petroleum gas \\
MDG & Millennium development goal \\
MGI & McKinsey Global Institute \\
NAMA & National appropriate mitigation actions \\
NGO & Non-governmental organization \\
OECD & Organization for Economic Cooperation and Development \\
PPP & Public-private partnerships \\
RED & Research and development \\
REDD & Reducing emissions from deforestation and degradation \\
REEEP & Renewable Energy and Energy Efficiency Partnership \\
SCF & Strategic Climate Funds \\
& Solar household system \\
\hline SHS &
\end{tabular}




$\begin{array}{ll}\text { TERI } & \text { The Energy Resources Institute } \\ \text { UN } & \text { United Nations } \\ \text { UNDESA } & \text { United Nations Department for Economic and Social Affairs } \\ \text { UNDP } & \text { United Nations Development Programme } \\ \text { UNEP } & \text { United Nations Environment Programme } \\ \text { UNF } & \text { United Nations Foundation } \\ \text { UNFCCC } & \text { United Nations Framework Convention on Climate Change } \\ \text { UNIDO } & \text { United Nations Industrial Development Organization } \\ \text { WEO } & \text { World Energy Outlook } \\ \text { WHO } & \text { World Health Organization }\end{array}$

\section{List of units}

GWh Gigawatt hours

kgoe kilogrammes of oil equivalent

kWh Kilowatt hours

m Million

Mtoe Million tons of oil equivalent

ppm Parts per million

tCO2e Tons of carbon dioxide equivalent 


\section{THE IMPORTANCE OF ENERGY}

${ }^{1}$ UNDP and WHO, 2009 estimates that over 3 billion people lack access to modern fuels for cooking and heating, while IEA 2009 estimates this number at 2.5 billion.

${ }^{2}$ Modern sources of energy include fuels such as natural gas, liquid petroleum gas (LPG), diesel and biofuels such as biodiesel and bioethanol. Technology, such as improved cooking stoves, can also enable cleaner and more efficient delivery of traditional fuels.

${ }^{3}$ World Bank, 2009b

\footnotetext{
${ }^{4}$ Carbon dioxide and the equivalent from other greenhouse gases
}

Energy is at the heart of most critical economic, environmental and developmental issues facing the world today. Clean, efficient, affordable and reliable energy services are indispensable for global prosperity. Developing countries in particular need to expand access to reliable and modern energy services if they are to reduce poverty and improve the health of their citizens, while at the same time increasing productivity, enhancing competitiveness and promoting economic growth. Current energy systems are inadequate to meet the needs of the world's poor and are jeopardizing the achievement of the Millennium Development Goals (MDGs). For instance, in the absence of reliable energy services, neither health clinics nor schools can function properly. Access to clean water and sanitation is constrained without effective pumping capacity. Food security is adversely affected, often with devastating impact on vulnerable populations.

Worldwide, approximately 3 billion people rely on traditional biomass for cooking and heating, ${ }^{1}$ and about 1.5 billion have no access to electricity. Up to a billion more have access only to unreliable electricity networks. The "energy-poor" suffer the health consequences of inefficient combustion of solid fuels in inadequately ventilated buildings, as well as the economic consequences of insufficient power for productive income-generating activities and for other basic services such as health and education. In particular, women and girls in the developing world are disproportionately affected in this regard.

A well-performing energy system that improves efficient access to modern forms of energy ${ }^{2}$ would strengthen the opportunities for the poorest few billion people on the planet to escape the worst impacts of poverty. Such a system is also essential for meeting wider development objectives. Economic growth goes hand in hand with increased access to modern energy services, especially in low- and middle-income countries transitioning through the phase of accelerated industrial development. A World Bank study ${ }^{3}$ indicates that countries with underperforming energy systems may lose up to 1-2 per cent of growth potential annually as a result of electric power outages, over-investment in backup electricity generators, energy subsidies and losses, and inefficient use of scarce energy resources.

At the global level, the energy system - supply, transformation, delivery and use - is the dominant contributor to climate change, representing around 60 per cent of total current greenhouse gas (GHG) emissions. Current patterns of energy production and consumption are unsustainable and threaten the environment on both local and global scales. Emissions from the combustion of fossil fuels are major contributors to the unpredictable effects of climate change, and to urban air pollution and acidification of land and water. Reducing the carbon intensity of energy - that is, the amount of carbon ${ }^{4}$ emitted per unit of energy consumed - is a key objective in reaching longterm climate goals. As long as the primary energy mix is biased towards fossil fuels, this would be difficult to achieve with currently available fossil fuel-based energy technologies. Given that the world economy is expected to double in size over the next twenty years, the world's consumption of energy will also increase significantly if energy supply, conversion and use continue to be inefficient. Energy system design, providing stronger incentives for reduced GHG emissions in supply and increased end-use efficiency, will therefore be critical for reducing the risk of irreversible, catastrophic climate change.

It is within this context that the UN Secretary-General's Advisory Group on Energy and Climate Change (AGECC) was convened to address the dual challenges of meeting the world's energy needs for development while contributing to a reduction in GHGs. AGECC carried out this task in a rapidly changing environment in which energy was often a key factor: the sensitivity of the global economy to energy price spikes; increased competition for scarce natural resources; and the need to accelerate progress towards achievement of the MDGs. The world's response to climate change will affect each of these issues. Pursuant to the Copenhagen Accord promulgated at the UNFCCC Conference of the Parties in December 2009, the Secretary-General has established a High-Level Advisory Group on Climate Change Financing. It is hoped that this report will be helpful to that and other similar initiatives. 


\section{THE IMPERATIVE TO TRANSFORM NATIONAL ENERGY SYSTEMS}

The central message of this report is that the international community must come together in a common effort to transform the global energy system over the coming decades, and that policy-makers and business leaders must place much greater emphasis on transforming the performance of national (and regional) energy systems over the coming decades. Low-, middleand high-income countries all face major, albeit different, transformational challenges:

Low-income countries need to expand access to modern energy services substantially in order to meet the needs of the several billion people who experience severe energy poverty in terms of inadequate and unreliable access to energy services and reliance on traditional biomass. They need to do so in a way that is economically viable, sustainable, affordable and efficient, and that releases the least amount of GHGs.

Middle-income countries need to tackle energy system development in a way that enables them progressively to decouple growth from energy consumption through improved energy efficiency and reduce energy-related GHG emissions through gradually shifting toward the deployment of low-GHG emission technologies.

High-income countries' face unique challenges. As the large infrastructure investments made in the 1960s and 1970s begin to reach the end of their economic lives, they present opportunities to further decarbonize their energy sectors through new investments in lower-carbon generation capacity. In addition, they will need to reach a new level of performance in terms of energy use.

While different national economies may pursue these transformational paths in distinct ways, there are large potential synergies from international cooperation, joint strategies and the sharing and adaptation of emerging best practices. These include lessons learned from policies and regulations, capacity development, technical standards, best available technologies, financing and implementation approaches, and more coordinated, scaled-up research and development.

By 2030, there is an opportunity for the world to be well on its way to a fundamental transformation of its energy system, allowing developing countries to leapfrog current systems in order to achieve access to cleaner, sustainable, affordable and reliable energy services. This change will require major shifts in regulatory regimes in almost every economy; vast incremental infrastructure investments (likely to be more than $\$ 1$ trillion annually) $;{ }^{5}$ an accelerated development and deployment of multiple new energy technologies; and a fundamental behavioural shift in energy consumption. Major shifts in human and institutional capacity and governance will be required to make this happen. The transformation of energy systems will be uneven and, if poorly handled, has the potential to lead to a widening "energy gap" between advanced and least developed nations, and even to periodic energy security crises. But handled well - through a balanced framework of cooperation and competition - energy system transformation has the potential to be a source of sustainable wealth creation for the world's growing population while reducing the strain on its resources and climate.

While there are various possible areas of focus in the broader energy system, AGECC has chosen two specific areas that present immediately actionable opportunities with many co-benefits: energy access and energy efficiency. 
${ }^{6}$ While UN-Energy is working on building consensus on an appropriate target for access to minimum energy services, this need not detain action. The lowest threshold is proposed by IEA, namely $100 \mathrm{kWh}$ per of electricity and 100 kgoe of modern fuels (equivalent to roughly $1200 \mathrm{kWh}$ ) per person per year. This can be used as a starting target.

${ }^{7}$ Affordable in this context means that the cost to end users is compatible with their income levels and no higher than the cost of traditional fuels, in other words what they would be able and willing to pay for the increased quality of energy supply in the long run (though it may be necessary to provide temporary subsides to reach affordability in the shorter run before economic development accrues).

${ }^{8}$ Energy intensity is measured by the quantity of energy per unit of economic activity or output (GDP).

\section{TWO KEY GOALS: ENSURING UNIVERSAL ENERGY ACCESS, REDUCING GLOBAL ENERGY INTENSITY}

\author{
AGECC calls on the United Nations system and its Member States to commit themselves to two
} complementary goals:

Ensure universal access to modern energy services by 2030. The global community should aim to provide access for the 2-3 billion people excluded from modern energy services, to a basic minimum threshold of modern energy services for both consumption and productive uses. ${ }^{6}$ Access to these modern energy services must be reliable and affordable, ${ }^{7}$ sustainable and, where feasible, from low-GHG-emitting energy sources. The aim of providing universal access should be to create improved conditions for economic take-off, contribute to attaining the MDGs, and enable the poorest of the poor to escape poverty. All countries have a role to play: the high-income countries can contribute by making this goal a development assistance priority and catalyzing financing; the middle-income countries can contribute by sharing relevant expertise, experience and replicable good practices; and the low-income countries can help create the right local institutional, regulatory and policy environment for investments to be made, including by the private sector.

Reduce global energy intensity ${ }^{8}$ by 40 per cent by 2030 . Developed and developing countries alike need to build and strengthen their capacity to implement effective policies, marketbased mechanisms, business models, investment tools and regulations with regard to energy use. Achieving this goal will require the international community to harmonize technical standards for key energy-consuming products and equipment, to accelerate the transfer of know-how and good practices, and to catalyze increased private capital flows into investments in energy efficiency. The successful adoption of these measures would reduce global energy intensity by about 2.5 per cent per year - approximately double the historic rate.

Delivering these two goals is key to achieving the Millennium Development Goals, improving the quality and sustainability of macroeconomic growth, and helping to reduce carbon emissions over the next 20 years.

There are also important synergies between these two goals. Modern energy services are more efficient than biomass, and the acceleration of energy access will also contribute to a more rapid reduction in net energy intensity. Increased energy efficiency allows existing and new infrastructure to reach more people by freeing up capital resources to invest in enhanced access to modern energy services. Similarly, energy-efficient appliances and equipment make energy services more affordable for consumers - residential, commercial and industrial. While there is no agreement as yet on the minimum target for universal energy access, the initial steps do not entail significant climate impacts. For example, IEA's recommended threshold of $100 \mathrm{kWh}$ per person per year, even if delivered through the current fossil fuel-dominated mix of generation technologies, will increase GHG emissions by only around 1.3 per cent above current levels. The impact of this increased energy consumption can be reduced through energy efficiency and a transition to a stronger reliance on cleaner sources of energy, including renewable energy and low-GHG emitting fossil fuel technologies, such as a shift from coal to natural gas. While each goal is worth pursuing independently, there will be clear synergies in pursuing them as part of an integrated strategy.

Although ambitious, these goals are achievable, partly because of technology innovations and emerging business models, and partly because of an ongoing shift in international funding priorities towards clean energy and other energy issues. There are also precedents for the widespread provision of both energy access (e.g., in China, Viet Nam and Brazil), and for dramatic improvements in energy efficiency (e.g., in Japan, Denmark, Sweden, California and China) that demonstrate the feasibility of achieving both goals. 


\section{RECOMMENDED ACTIONS TO ACHIEVE THE GOALS}

AGECC recommends the following actions toward achieving the two goals of ensuring universal energy access and of reducing global energy intensity:

\section{A global campaign should be launched in support of "Energy for Sustainable Development."}

This campaign would be focused on improving access to modern energy services and enhancing energy efficiency, as well as raising awareness about the essential role of clean energy in reaching the MDGs while addressing climate change, promoting economic growth and conserving natural resources and biodiversity. The campaign should ensure that energy is made an integral part of the MDG review process in 2010 as well as other major inter-governmental processes - including those on climate change, biodiversity, desertification, food security, and sustainable development. The campaign should encourage the United Nations and its Member States, other multilateral institutions, and the private and non-profit sectors to take the actions needed to achieve its goals.

\section{All countries should prioritize the goals through the adoption of appropriate national} strategies.

National strategies should create a predictable, long-term policy environment for investment and a road map for accelerating the establishment of the required human and institutional capacity and delivery mechanisms.

For high-income countries, this may entail: (a) national plans to benefit from the energy efficiency dividend; (b) increased investment in R\&D; and (c) more focused commitments to support developing countries in helping to achieve their goals in the areas of both energy access and efficiency.

For middle-income countries, this may involve: (a) national plans to capture the energy efficiency opportunities as an integral part of their National Appropriate Mitigation Actions (NAMAs) and Low Carbon Growth Plans (LCGPs); (b) targeted interventions to reduce residual pockets of energy poverty; (c) a phased withdrawal of untargeted energy subsidies; and (d) technical support for the energy access and efficiency programmes of low-income countries.

For low-income countries, this may require: (a) national plans to accelerate the deployment and provision of modern energy services; (b) incorporation of these plans, if based on low-GHG emissions technologies, into their NAMAs/LCGPs; (c) re-orienting regulatory policy frameworks, including tariff structures and market regimes, to stimulate business innovation and private sector participation; (d) improvement in the design and careful targeting of energy subsidies; (e) further investment in the capabilities of public utilities; and (f) a phased introduction of lowGHG emitting technologies, as well as energy efficiency measures wherever feasible.

In a broader context, all countries have to work towards: (a) accelerated harmonization of technical standards for energy-using products and equipment; (b) increased R\&D investments, especially in technologies that would reduce the cost and GHG intensity of energy services; and (c) trade-related measures that would support market expansion for products that increase energy efficiency or enhance access.

\section{Finance, including innovative financial mechanisms and climate finance, should} be made available by the international community.

A combination of financial support mechanisms and a significant increase in international finance - both bilateral and multilateral - will be needed to catalyze the existing public sector funding mechanisms and to leverage increased private sector investments, in order to meet the capital requirements needed for providing access to modern energy services and energy efficiency programmes in low- and middle- income countries.

For universal access to modern energy services to meet basic needs, ${ }^{9}$ it is estimated that $\$ 35-40$ billion $^{10}$ of capital will be required on average per year to achieve basic universal access by 2030 .
${ }^{\mathbf{9}}$ Energy required for cooking, heating, lighting, communication, healthcare and education.

${ }^{10} \$ 35$ billion per year for electricity access estimated by IEA, 2009 , and \$2-3 billion per year for modern fuels access based on cost estimates from UNDP and ESMAP, 2005a 
$\mathbf{1 1}^{\mathbf{1 1}}$ This is based on an access level sufficient to meet basic human needs. As levels of infrastructure increase in order to allow for productive use, the loan capital requirements will increase, but the associated increased income generating capacity wil improve people's ability to pay for these services.

${ }^{12} \mathrm{CIF}$ is a new source of financing to pilot projects to initiate transformational change towards low-carbon and climate-resilient development. The CIF funds, to be disbursed as grants, highly concessional loans, and/or risk mitigation instruments, are being administered through the multilateral development banks and the World Bank Group for quick and flexible implementation of country-led programmes and investments. CIFs consist of the Clean Technology Fund (CTF) and the Strategic Climate Fund (SCF). More details are available on http://www.climateinvestment funds.org/cif
We estimate that around $\$ 15$ billion of grants would need to be made available, mainly to cover the capital investment and capacity building required in least developed countries, where national energy investments are likely to focus on overcoming infrastructure backlogs and meeting suppressed demand in productive sectors. In addition, $\$ 20-25$ billion of loan capital will be required for governments and the private sector above business-as-usual. ${ }^{11}$

For energy efficiency, our estimate is that on average \$30-35 billion of capital is required for low-income countries and \$140-170 billion for middle-income countries annually until 2030 above the IEA's reference case. In general, most energy-efficiency investments are cost-effective. In practice, however, costs of energy-efficiency are typically mostly front-loaded, with the benefits accruing over time, and low-income countries often have access to limited and expensive capital, which they prefer to invest in the cheapest (first-cost) options available to attain their energy goals. This is also a challenge for many consumers - residential, commercial and industrial - who look for investments with quick payback periods of typically 2-3 years. Financial support in terms of innovative financial structuring such as concessional loan finance, loan guarantees and other financial instruments, supplemented by other market mechanisms, helps to address the risks and barriers, and leverages private capital.

To support investment in energy access and efficiency, climate finance could be mobilized through two key strategies:

(a) Funds could be made available from the $\$ 30$ billion "Fast Start Funding" committed in COP15 under the Copenhagen Accord for 2010-2012, especially for strategy, policy and capacity development. This could be in line with the Global Environment Facility (GEF), or the newlyestablished, multi-lateral development bank-administered Climate Investment Funds (CIF) which already has donor commitments of $\$ 6$ billion. ${ }^{12}$ In the medium to long term, the SecretaryGeneral's High-Level Advisory Group on Climate Change Financing could make it a priority to address the financing needs for energy efficiency and low-carbon energy access investments.

(b) In parallel, innovative use of carbon markets could expand the effectiveness of the Clean Development Mechanism and other market-based mechanisms as vehicles for the mobilization of incremental funds.

All support should aim at scaling up financial instruments that mitigate the risk of commercial lending for energy access and energy efficiency, and therefore leverage increased private sector participation over time.

4. Private-sector participation in achieving the goals should be emphasized and encouraged.

In the first instance, this will require the creation of long-term, predictable policy and regulatory frameworks to mobilize private capital. Within this context, major opportunities to enhance private participation may include:

(a) Implementing more public-private partnerships (PPPs) that have the potential to accelerate deployment of technologies that improve energy efficiency and/or enhance energy access (especially on the basis of low emissions). These could be akin to successful PPPs in the global public health arena and could catalyze a scaling up of funding for research, development, and commercial demonstration of low-carbon technologies, especially to close the energy access gap.

(b) The creation of new and innovative investment mechanisms to enable accelerated technology deployment with active private-sector participation - e.g., through a network of regional cleanenergy technology centres to hasten the spread of locally appropriate energy technologies.

(c) An expansion of local lending capabilities to scale up investments in energy efficiency and access through local commercial banks and micro-finance institutions.

(d) Many countries have established regulatory and incentive frameworks for attracting private capital into the energy sector. These include a separation of regulatory, generational, transmission, and distribution functions; the announcement of capacity targets; transparent long term tariff offers; and coverage for political risk (but not for economic risk). Successful models could be transferred to other countries through South-South cooperation. 
(e) The existing systems could be adapted to the emerging challenges, e.g., by adding special incentives for off-grid areas, the deployment of renewables (feed-in tariffs), and R\&D. Incentives for off-grid areas may include the expansion of local lending for energy efficiency and access through local banks and micro-finance institutions referred to under (c) above. ${ }^{13}$

(f) The envisaged technology mechanism under the UNFCCC could also be mobilized in this regard. One approach could be to increase private sector participation in the network of regional clean-energy technology centres to hasten the spread of locally-appropriate energy technologies

\section{The United Nations system should make "Energy for Sustainable Development" a major institutional priority.}

This may be achieved as follows:

(a) Facilitating energy access and improving energy efficiency should be integrated and mainstreamed into all relevant programmes and projects of the United Nations system, and Member States should be encouraged to do the same.

(b) Technical and financial support should be provided to help governments formulate appropriate plans, policies and regulations and develop local institutional capacities to enable their effective delivery, with a focus on "delivering as one" through United Nations country teams, supported and facilitated by UN-Energy.

(c) Existing knowledge networks should be mobilized and new ones built with partners outside the United Nations system to accelerate the transfer of best practices (with respect to modern energy system policies and regulations) by (i) mobilizing expertise across multilateral, public and private organizations; (ii) designing targeted, technical interventions; ${ }^{14}$ (iii) providing a registry of donor projects to facilitate improved coordination; and (iv) creating and sharing diagnostic tools, technical software and know-how for policy-makers and practitioners. The UNEPled Global Network on Energy for Sustainable Development (GNESD) provides a good example of knowledge creation and sharing on energy policy analysis.

(d) A monitoring and evaluation system for "Energy for Sustainable Development" should be created and coordinated to allow dynamic tracking of national (and sub-national, e.g., city) progress over time.

(e) A mechanism for regular global dialogue on "Energy for Sustainable Development" should be established, including a secretariat to manage the process.

(f) A strengthened UN-Energy framework could serve to spur progress toward a number of these objectives.
13 Off-grid examples exist in Sri Lanka and Bangladesh where IDA and GEF have set up centrally-coordinated credit systems leveraging existing micro-finance institutions to create flexible payment options for solar household systems (ESMAP, 2008; Vipradas)

\footnotetext{
${ }^{\mathbf{1 4}}$ For example, the Global Gas Flaring Reduction Initiative
} 


\section{ENERGY ACCESS AND ENERGY EFFICIENCY: ANALYTICAL OVERVIEW}

This section sets out the analytical underpinning of the key recommendations on energy access and energy efficiency.

\section{A. ENERGY ACCESS}

One of the challenges facing the global development community is that there is no clear consensus on what the term "energy access" means. For the sake of simplicity, one can consider three incremental levels of access to energy services and the benefits they can provide (see Exhibit 1):

Pending further analysis of the interlinkages between these uses, for the purposes of this report we have defined universal energy access as "access to clean, reliable and affordable energy services for cooking and heating, lighting, communications and productive uses" - i.e., levels $1+2$. Even a basic level of electricity access that replaces other sources of fuel for purposes such as lighting and allows for communication, healthcare and education can provide substantial benefits to a community or household, including cost savings. However, we have adopted this broader definition because access to sufficient energy for basic services and productive uses represents the level of energy access needed to improve livelihoods in the poorest countries and drive local economic development on a sustainable basis. "Affordable" in this context means that the cost to end users is compatible with their income levels and no higher than the cost of traditional fuels, in other words what they would be able and willing to pay for the increased quality of energy supply. If the cost of the minimum energy package to end users should be more than a reasonable fraction of their income (10-20 percent), it may be necessary to provide temporary subsidies to reach affordability in the shorter run before economic development accrues. This provides an additional reason why energy for productive uses is so critical: it increases end users' ability to pay for energy services, which is key to the long-term financial viability of such services.

While universal access only to the most "basic human needs" levels of energy services will have a limited impact on greenhouse gas emissions (basic universal electricity access would add around 1.3 per cent of total global emissions in 2030, according to the IEA), ${ }^{15}$ increasing the level of energy provision and consumption for productive uses could increase emissions substantially. This under-

\section{Exhibit 1 Incremental levels of access} to energy services

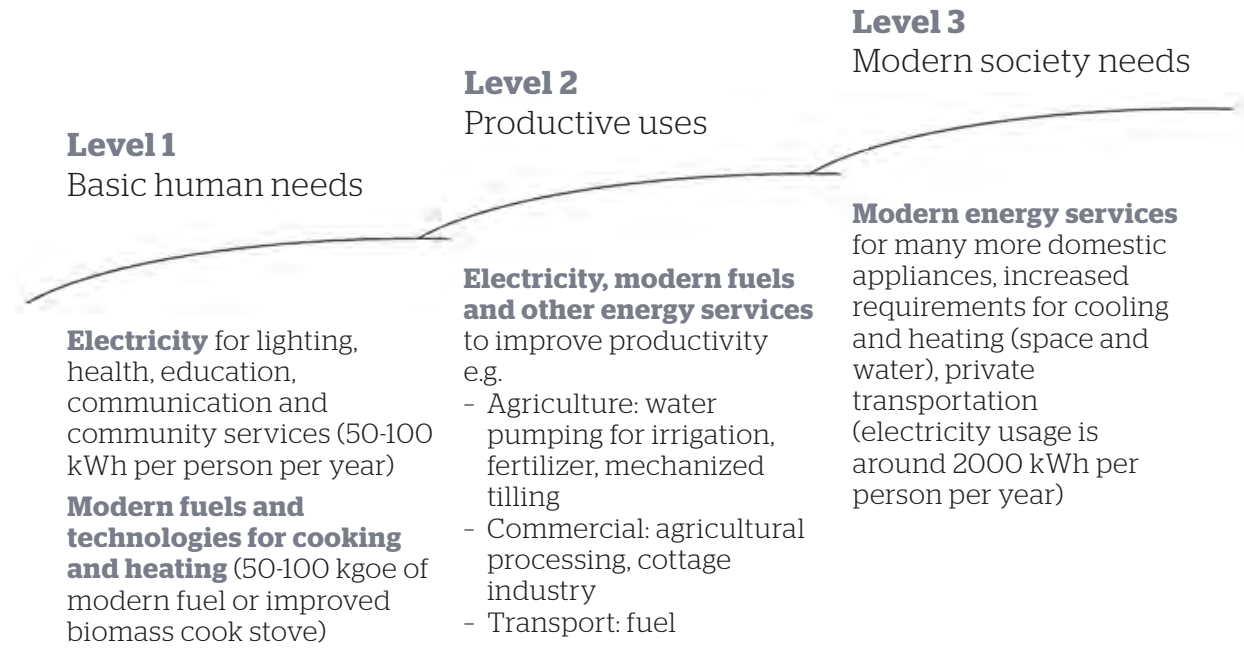


scores the importance of driving down costs of low-emissions technologies to enable accelerated deployment, to the extent feasible, both on the supply side (including lower-emissions fossil fuelbased technologies) and the demand side, where energy-efficient end-use devices reduce the amount of power consumed. Ensuring access to these technologies and developing new products and services geared to the needs of low-income communities is therefore critical.

Achieving universal energy access is an ambitious goal. The scale of the task is daunting and requires overcoming complex challenges in some of the poorest and most remote locations on the globe. Access to modern energy services will require a combination of electricity and modern fuels and technologies. Currently, more than 1.5 billion people have no access to electricity, and up to a billion more have access in name only because their power supply is highly unreliable. An estimated 2.5 to 3 billion people rely on biomass and transitional fuels, such as coal and kerosene for cooking and heating. ${ }^{16}$

Providing universal energy access will pose a number of critical challenges related to overcoming gaps in the local institutional capacity and governance required to produce, deliver, manage, operate and maintain these solutions (including strengthening the capabilities of public sector utilities to operate commercially without political interference). Additionally, accessing and allocating sufficient financing will be a major obstacle. In order to stimulate economic growth, many countries naturally prioritize investment in power infrastructure for the productive industrial and commercial sectors (closing the existing supply gap or improving the performance of the ailing utilities and power-generating infrastructure) over providing basic energy access for all. ${ }^{17}$

At the same time, the goal of universal energy access is achievable, if the right elements are put in place. The capital investment required for "basic human needs" level of access (\$35-40 billion per year ${ }^{18}$ to 2030 ) represents only around 5 per cent of the total global energy investment expected during this period. While even more people need access to modern fuels for cooking and heating, the capital costs of closing this gap are substantially lower than for electricity. It is estimated that, on average, grant funding of around \$10-15 billion a year and loan capital of \$2025 billion a year will be needed, with the remainder self-financed by developing countries. The incremental investment required to provide sufficient energy for productive use $\mathrm{e}^{19}$ would be almost entirely for concessional loan capital rather than grant funding. This is because the additional energy capacity will provide people with opportunities for income generation and therefore increase their ability to pay for the energy services, thereby increasing the financial viability of these services.

There are various successful examples of significant scale in the developing world that demonstrate that this is possible. More new household electricity connections were made in the 1990s than would be required in each of the next two decades to achieve universal access (see Exhibit 2). This extension occurred mainly in Asia (especially China, Viet Nam and Thailand), but South Africa and Brazil also achieved notable successes in rural electrification.

While the challenge in the future will increasingly be that people who lack access will be more dispersed, more rural, ${ }^{20}$ and have lower incomes, and will therefore require higher subsidies in the face of a limited availability of resources to meet higher capital costs, the technologies and business practices required to overcome these obstacles already exist and are evolving rapidly.

Access to electricity: The scale and nature of the access gap and the locations involved means that electricity will need to be provided through both centralized and decentralized energy technologies and systems, combining the following three basic approaches:

Grid extension. An extension of the existing transmission and distribution infrastructure to connect communities to power.

Mini-grid access. Linking a local community to a small central generating capacity, typically located in or close to the community. The power demand points are linked together in a small, low-voltage grid that may also have multiple smaller generating sources.

- Off-grid access. Generating capacity for a single point of demand, typically a solar household system (SHS).
${ }^{16}$ IEA 2009 estimates 2.5 billion people lack access to modern fuels for cooking and heating, while UNDP \& WHO, 2009 estimate that this number is over 3 billion people.

${ }^{17}$ According to World Bank 2009 b, \$40 billion per year for the next ten years is required to overcome the challenges currently facing the African power sector.

${ }^{18} \$ 35$ billion per year for electricity access estimated by IEA 2009 and \$2-3 billion per year for modern fuels access based on cost estimates from UNDP and ESMAP, 2005a

${ }^{19}$ Increased electricity generating capacity and other energy related infrastructure would be required to require mechanical power. 
Lessons from the 1990s indicate that the scale of universal electricity access challenge is not insurmountable

\author{
Average number of households gaining access to electricity \\ Millions
}

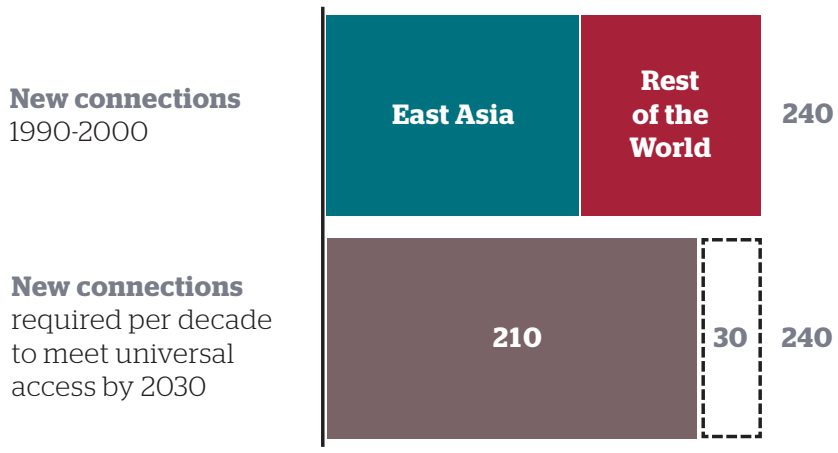

Implementation had to

be done with great

speed and intensity:

In the early 90s, China

was electrifying over

30 villages a day

Viet Nam granted almost 400 people access to electricity per hour for 15 years

South Africa made a new grid connection every 30 seconds, placed a pole in the correct position every 10 seconds and strung $200 m$ of cable every minute

${ }^{21}$ World Bank, 2009b

\footnotetext{
22 Jiahua et al., 2006 and IEA, 2010; World Bank, 2009a; World Bank/IDA, 2000; ASTAE, 2008; Stephen \& Sokopo, 2006; Marquard et al., 2007
}

The critical question in electricity access is not which of these solutions should be adopted, but rather what combination of these solutions should be adopted. The optimal mix for each country would be driven by the availability of resources, the regulatory and policy environment, the institutional and technical capacity, and the relative costs of each of these solutions. Each comes with its own set of advantages and challenges, and the highest impact will be achieved when grid, mini-grid and off-grid solutions are appropriately traded off and then combined to resolve the challenges in each different market.

The trade-off between grid solutions, mini-grid solutions and off-grid solutions will need to take into account several critical factors - including the level of energy access required in each community and the likely time taken to roll out the different solutions - which will depend in part on local conditions and available natural resources. These elements are not static, and the decisions taken will need to consider their expected evolution.

Grid extension is often the least-cost option in urban areas and in rural areas with high population densities. If pursued at the regional level, especially in Africa, it also offers the opportunity to tap into significant hydropower potential, providing low-cost clean energy. ${ }^{21}$ A number of factors underpin successful grid extension, including strong government commitment but limited political intervention, a clearly defined role for national utilities, excess generating capacity, and a focus on reducing capital costs, inter alia by increasing the economies of scale of the connections.

For large-scale grid extension to be feasible, the system needs to be functioning well enough to support the additional capacity and demand, and to enable recovery of costs. In many developing countries this is not the case and would require a refurbishment of the existing infrastructure, improvement of the performance of the utilities through local capability building, implementing best practices for operational improvements (e.g., loss reduction programmes), and resolving fuel supply issues by ensuring that appropriate fuel supply chains and logistics infrastructure are established. In countries where electricity and primary energy prices are regulated and subsidized, steps would need to be taken towards establishing tariff structures reflective of costs.

There are a number of compelling global examples of successful large-scale grid extension, including China (more than 700 million people connected), Viet Nam (95 per cent of households connected) and South Africa (more than 2.5 million households connected in less than 7 years). ${ }^{22}$ 
Large-scale grid-based electrification programmes have historically utilized predominantly fossil fuel-based generating technologies. This was certainly the case in China, where electrification was driven by a rapid expansion of coal-fired plants, and in South Africa, where the programme leveraged significant over-capacity that had already been installed. In the medium term, fossil fuels are likely to continue to play a major role. Deploying low-carbon-emitting fossil fuel technology solutions, such as natural gas, carbon capture and storage (CCS), high efficiency coal-fired stations, and exploring even newer technologies such as underground coal gasification will therefore be critical to reduce emissions. Mechanisms to cover the additional costs associated with cleaner grid-based generation technologies will need to be developed and utilized.

In rural areas and remote settlements further from the grid, mini-grid and off-grid solutions may be more attractive, since they can be deployed more rapidly than grid solutions and do not require excess generation capacity. Moreover, there is often a significant local business-building and job creation potential from these solutions. Their levelized costs relative to grid-based solutions depend on a variety of factors, in particular the capital cost of the generation technology (in part related to capacity of supply required) and distance from the existing grid. Renewable energy technologies, including small hydro, solar, wind and various types of bio-energy, are ideally suited to mini-grid and off-grid applications, especially in remote and dispersed rural areas. While the costs of non-hydro, renewable energy-based sources are typically somewhat higher than fossil fuel-based technologies, the learning curve associated with their increased deployment is resulting in increasing cost-competitiveness.

The key challenges related to both mini-grid and off-grid solutions include significant initial capital investments, the capabilities required to install and maintain these systems, and defining and implementing appropriate pricing systems. These challenges have been successfully overcome in numerous developing countries (e.g., Bangladesh, Tunisia). ${ }^{23}$ Mini-grid systems have added operating complexity and costs, including load balancing. However, in many cases the value of aggregating supply at community level so that it is available for productive use during non-peak hours for household use will outweigh the costs. Mini-grids played an important part in rural electrification in China, and there are more recent success stories in Sri Lanka and Mali. ${ }^{24}$ Minigrids can also serve as an intermediate step to grid access (as in China), which makes design for compatibility with the grid an important consideration. In order to augment rural electrification, under a GEF-funded Strategic Energy Programme for West Africa, ${ }^{25}$ renewable energypowered mini-grids linking to productive uses are being established in eight countries.

For all types of electricity access, past experience shows that no single institutional model reliably provides better success rates than others. Both large-scale vertically integrated utilities and smaller decentralized businesses can deliver the required solutions, using public, private and cooperative approaches, ${ }^{26}$ depending on the strength of the existing utilities and local businesses. In all cases, however, a degree of central programme-level coordination is necessary. ${ }^{27}$

Cost recovery is essential for the ongoing sustainability of services. Governments need to decide what tariff structures and cost-recovery mechanisms (e.g., lifeline tariffs or cross-subsidies) to put in place based on the ability and willingness to pay, which will vary according to income levels and the availability of alternative energy sources in the different regions. For example, lifeline or free basic electricity allocations are set at $10 \mathrm{kWh} /$ month per connection in the Philippines; at 300 $\mathrm{kWh} / \mathrm{month}$ in Zambia; and at $50 \mathrm{kWh} /$ month in South Africa. ${ }^{28}$

Access to modern fuels and technologies: There is a wide variety of modern fuels, including natural gas, LPG, diesel, and renewables such as biodiesel and bio-ethanol. There are also many technology options to make use of modern fuels, or use traditional fuels more efficiently, such as improved cooking stoves.

The suitability of these options depends on factors such as availability, applicability, acceptability and affordability, including access to finance to cover initial investments. The decreasing availability of existing sources of fuel makes switching to modern alternatives a necessity in some places. For example, in many parts of India finding sufficient biomass for cooking is becoming increasingly difficult. 
29 For more modern fuel applications see recent FAOPISCES 2009 "Small-Scale Bioenergy Initiatives: Brief description and preliminary lessons on livelihood impacts from case studies in Asia, Latin America and Africa"

${ }^{30}$ Bajgain \& Shakya (2005)

${ }^{31}$ Limmeechokchai and Chawana, 2004

${ }^{32}$ UNDP expert interviews, ESMAP 2005a

33 UNIDO/Africa Union Report 2008. Scaling up Renewable Energy in Africa: Action Plan adopted by the International Conference on Renewable Energy in Africa, April 2008, Dakar, Senegal.
To illustrate the challenges related to providing access to modern fuels and technologies, we have focused on cooking needs, using LPG, biogas and improved cooking stoves. These options do not represent the full range of needs or applications for modern fuels; ${ }^{29}$ they have been chosen as examples of solutions that have been implemented at scale.

LPG is widely utilized in cooking applications, providing much more efficient use of energy than biomass. The challenge is that operating costs are relatively high (and subject to global oil price fluctuations), so LPG is typically a financially viable alternative only where households are already making a financial payment for energy (e.g., buying charcoal). This will usually, although not exclusively, be the case in urban or semi-urban areas, where roughly 20 per cent of people without access to modern fuels live. Large-scale LPG programmes in Brazil and Senegal demonstrate that rural distribution challenges can be overcome, while at the same time creating local jobs and livelihoods. However, it must be noted that the subsidies required in these countries to increase adoption are a significant drain on government resources, and may be unaffordable to many least developed countries.

There is a strong case for biogas where people own sufficient livestock: the dung from two cows typically suffices to meet the cooking requirements of a household. ${ }^{30}$ As the fuel is produced on site, there are few distribution challenges or costs beyond the delivery of the equipment. Even though a higher initial investment is required than for the other options discussed here (and access to finance therefore needs to be provided), the absence of ongoing fuel costs mean that the annualized cost over the lifetime of the equipment is significantly lower than that for non-renewable modern fuels. ${ }^{31}$

For people who lack access to sufficient livestock and biomass for biogas production and who are unable or unwilling to pay for LPG/natural gas solutions, one further option is to improve the efficiency with which they burn biomass. Here improved cooking stoves offer a feasible alternative. These stoves provide numerous advantages: they double or triple the thermal efficiency of traditional fuels, reduce the harmful effects of poor ventilation, and may also provide some co-heating. They ameliorate a number of serious health and environmental problems caused by current practices - the premature death of more than 1.5 million people a year, mostly women and children, from pulmonary disease caused by smoke inhalation; the time spent and physical risk to women foraging for fuel, degrading forests and ecosystems; and the climate change impacts of black carbon emissions. More efficient stoves are relatively inexpensive (\$15-60 per unit $/ \$ 3-12$ per person). ${ }^{32}$ However, experience has shown that higherquality, more durable models (with associated higher costs) stand a much better chance of success of sustained impact.

For all the modern fuels solutions, substantial awareness - both of the benefits new fuels and technologies provide and of how to use them - is essential to ensure uptake. In addition, the development of local capabilities to maintain new technologies (e.g., stoves, biogas digesters) is crucial to success. This should be viewed not as an obstacle but as an opportunity for the creation of sustainable livelihoods. In addition, policy and regulatory frameworks are critical triggers for scaling up investments in renewable energy projects. ${ }^{33}$

Given the lessons learned from programmes around the world to provide access to electricity and modern fuels, both those that have been highly successful and those that have not, a number of building blocks are needed, at national and international level. These building blocks require the mobilization of resources and support across a range of actors in different countries:

Top agenda item for government: Governments need to prioritize energy access, set aggressive national targets for universal access, and put in place plans and the enabling environment to deliver them. Successful large-scale electrification programmes are underpinned by government targets and priorities that inform a rigorous planning process, legislation and regulation. This process is typically supported by multilateral organizations, international agencies, and non-profit organizations.

Access to financing: Given the scale of the effort, access to various sources of financing is critical, particularly for the initial capital. This will typically come from a combination of 
government subsidies, concessional loans from various sources, grants, cross-subsidization, and end-user tariffs.

- Capacity building: Real focus is required on building the capabilities and capacities of local institutions for delivery, quality monitoring, financing, and operations and maintenance services. The public and private sector should leverage and build on the expertise and knowledge base that has been developed by their global counterparts, as well as multilateral institutions and international agencies.

Utility performance: Improving the performance of public utilities is critical to the success of expanding the grid and achieving the universal access target, as in developing countries, utilities often have technical losses at rates four or five times higher than developed countries. Expertise from the private sector in the developed and developing world should be leveraged to drive these utility improvements.

Providing global energy access is not a luxury, but a necessity. Lack of access to modern energy services is one of the main factors that keep the poor poor. Providing access to reliable and affordable sources is critical for development, and increasing the reliance on clean energy sources for energy access is also important for the climate agenda. Access solutions will vary by geography, by setting and over time. But there are many successful examples of access expansion to imply that the ambitious goal of universal energy access by 2030 is achievable.

\section{B. ENERGY EFFICIENCY}

There is a strong correlation between energy consumption and economic growth, and the term "energy intensity" ${ }^{34}$ provides a way of understanding the evolution of this relationship. Energy intensity can be reduced in two ways: First, higher energy efficiency can reduce the energy consumed to produce the same level of energy services (e.g., a more efficient bulb produces the same light output for less energy input). Second, the economic structure of individual markets can shift from high energy intensive activities such as manufacturing to low energy intensive activities and sectors such as services, while keeping same or higher levels of total GDP. Since 1990, global energy intensity has decreased at a rate of about 1.3 per cent per year due to both structural effects as well as physical energy efficiency improvements.

Energy efficiency is the key to driving incremental reductions in energy intensity. It is one of the few "no-regret" policies that can offer a solution across challenges as diverse as climate change, energy security, industrial competitiveness, human welfare and economic development. While it offers no net downside to energy-consuming nations, the benefits have proved difficult to capture. In recent decades, however, some developed countries and regions such as Japan, Denmark and California have been able to decouple economic growth from energy growth, in part due to major and sustained energy efficiency efforts.

Capturing all cost-effective ${ }^{35}$ energy efficiency measures could reduce the growth in global energy consumption from the currently forecast levels of 2,700-3,700 million tonnes oil equivalent (Mtoe) in 2030 to 700-1700 Mtoe (see exhibit 3). This would represent a reduction in energy consumption growth of some 55 to 75 per cent from the business-as-usual case. It would also have a significant effect on emissions: energy efficiency opportunities make up about a third of the total low-cost opportunities to reduce GHG emissions globally, with forestry, agriculture and a move to low-carbon energy supply representing the balance of the opportunity. ${ }^{36}$

The vast majority of energy demand growth is expected to come from lower-middle-income countries such as China and India, driven by rapid industrialization and an increasingly wealthy population scaling up demand for cars, household appliances and other energy-consuming products. The energy efficiency savings potential, however, is split almost evenly between highincome countries and the rest of the world, due to the retrofitting opportunities on the large existing stock of infrastructure in the developed world. In most countries, the untapped potential for improvements is available across the supply and demand side, in various sectors of the economy.

\footnotetext{
${ }^{34}$ Energy intensity is measured by quantity of energy per unit of economic activity or output, so that using less energy reduces the intensity of the output.
} 


\section{Exhibit 3}

\section{Growth expected to continue to come mainly from the lower-middle income, with highest energy efficiency potential in high income countries}

Low income

Lower-middle income

upper-middle income

High income

\author{
Global final energy consumption
}

Mtoe

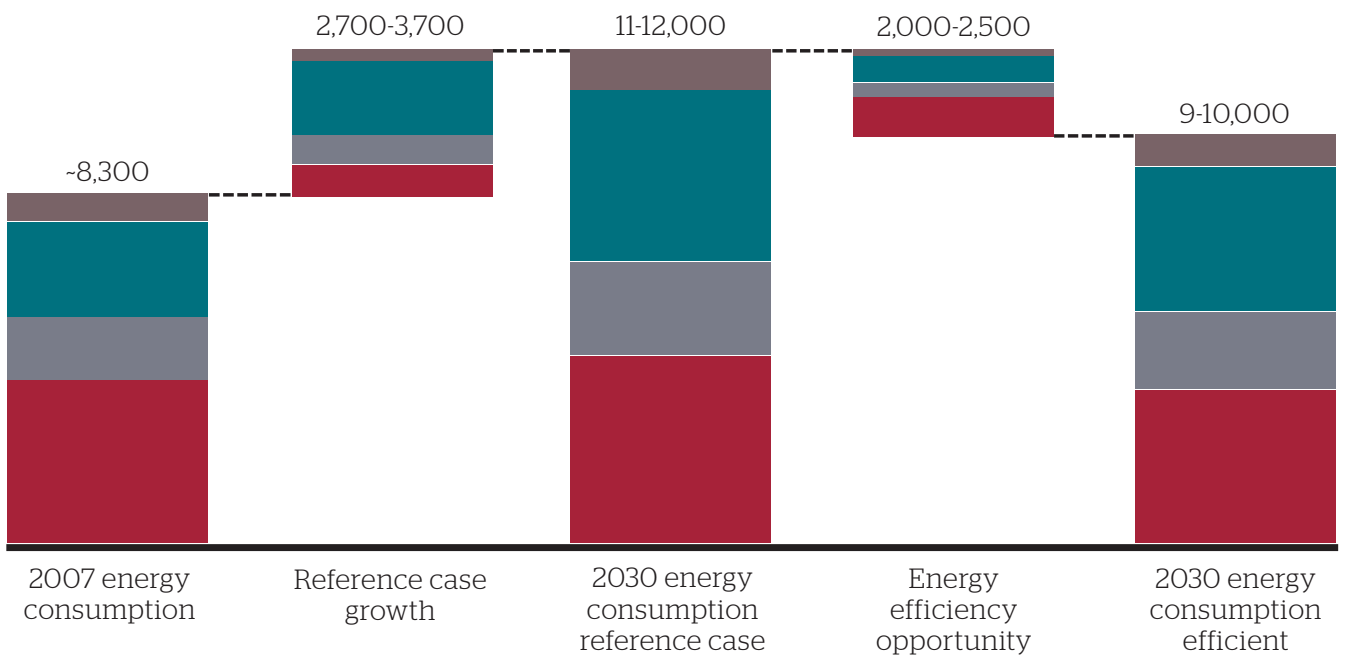

${ }^{37}$ Defined as opportunities costing less than $\$ 90 / \mathrm{tCO}_{2} \mathrm{e}$ in the McKinsey Global GHG Abatement Cost Curve v2.0

${ }^{38}$ IEA, 2008a; IEA, 2009

\footnotetext{
39 The potential is estimated by looking at more than 80 individual measures that are economically positive; McKinsey Global GHG Abatement Cost Curve v2.0; IEA 2009.

40 This achievement has resulted in a major UNIDO-GEF programme that now covers twelve countries, and it has served as a worldwide call for systems optimization. See UNIDO 2005.

41 IEA 2008b; UNIDO analysis
}

If the full identified low-cost ${ }^{37}$ energy efficiency improvement potential were captured, global energy intensity would decrease by 2.2-2.7 per cent per year. This is compared with the reference case $^{38}$ of 1.3-1.7 per cent, which is similar or slightly higher than the historic rate. This potential only represents current available technologies and therefore could prove even larger, taking into account future breakthrough technologies or behavioural change, which could provide substantial additional gains in efficiency.

In recent decades, some developing countries have also been increasing their GDP significantly faster than their energy consumption, leading to a reduction in their energy intensity. In absolute terms, however, developing countries' average energy intensity level is three times that of the developed countries.

There are substantial energy efficiency improvement opportunities on both the supply side and the demand side. On the supply side, the power sector in the developing world in particular has substantial potential to improve the efficiency of power generation and to reduce transmission and distribution losses, thereby reducing the amount of primary energy (e.g., coal, gas, oil) consumed for the same output. ${ }^{39}$ In many respects, this kind of supply-side potential is easier to capture in the short to medium term, as there are fewer institutional barriers than on the demand side. Improving power sector efficiency is also directly linked to improving energy access, as discussed earlier in this report.

The demand side includes end-use efficiency opportunities in industry, buildings and transport. For instance, a UNIDO project funded by the Global Environment Facility $(\mathrm{GEF})^{40}$ on motor systems energy efficiency in China yielded an average 23 per cent improvement, with a payback period of well below two years. If best available technologies were applied worldwide today, the largest potential savings exist in buildings (in the order of 1500 to 2000 Mtoe in primary energy) and power generation (around 1000 Mtoe), followed by industry (600 to 900 Mtoe) and transport (on the order of 500 Mtoe). ${ }^{41}$ 
The type of response will differ by sector. For buildings, much will depend on the widespread uptake of energy-efficient electric equipment and efficient lighting. Improvements in building envelopes and structures constitute an important opportunity in temperate and cold climates, and also for new buildings in hot climate zones, where design can reduce cooling loads. In the transport sector, a mix of energy-efficient vehicles including all-electric and hybrid electric vehicles, integrated traffic planning and modern public transportation systems can create significant gains. In industry, special attention should be focused on small and medium-size enterprises and on systems approaches that go beyond the process or technology level.

In many sectors, the nature of the opportunity is similar for both developed and developing countries. In sectors with long-life assets, however, it differs. In developing countries, much of the energy efficiency potential in buildings, industry and power is associated with greenfield opportunities (i.e., new buildings, new industrial stock). There is a need to move quickly on these infrastructure opportunities: continuing to expand the use of energy-inefficient solutions can lock in infrastructure that will require high energy consumption and carbon emissions for 40 years or more. While retrofit opportunities do exist, they tend to be more expensive.

On a life-cycle cost basis, most energy efficiency opportunities are characterized as having "negative cost": in other words, the savings from reduced energy consumption over the lifetime of the investment exceed the initial cost. It is estimated ${ }^{42}$ that the total financial savings, or avoided energy cost, of the global efficiency opportunity is $\$ 250-325$ billion a year in 2030 . Additional benefits include the environmental benefit - a reduction of 12-17 per cent of total global GHG emissions in 2030 versus a baseline scenario, which is around a third of the low-cost GHG abatement opportunity $^{43}$ - and the economic benefit of reducing the risk of price volatility as a result of demand outstripping supply. When coupled with other low-cost abatement actions such as renewable power and reduced deforestation, this path is compatible with a $450 \mathrm{ppm}$ stabilization scenario. ${ }^{44}$

In addition to the benefits shared by the global community, countries that succeed in increasing energy efficiency can also reap a number of direct benefits at different levels:

- Governments. Energy efficiency can ease infrastructure bottlenecks by avoiding or delaying capital-intensive investments in new power supply without affecting economic growth. This is especially important in developing countries, where there are energy supply shortages and significant capital constraints. The IEA estimates savings of $\$ 1$ trillion in avoided energy infrastructure investment to 2030 if the available energy efficiency potential is captured. ${ }^{45}$ Reducing peak load through load management can reduce generation costs. Reducing overall generation through energy efficiency reduces fuel imports (primarily oil and gas), which lowers import dependence, reduces import bills and overall energy costs, and improves the competitiveness of the economy. ${ }^{46}$ In sectors with energy subsidies, energy efficiency helps mitigate the burden on the Government budget. In terms of project economics, energy efficiency options almost always have positive financial returns and are almost always cheaper than installing new supply.

- Consumers. Energy efficiency allows lower energy consumption for the same end-use energy services, which lowers energy costs for consumers - industrial, commercial and residential. This leads to higher affordability, which is particularly important for low-income groups, and creates a more attractive environment for tariff reform. At the same time, reducing energy demand leads to higher system reliability, which in turn lowers outage costs and raises productivity and income.

Energy efficiency can also generate significant employment from additional business activities in the manufacturing and service sectors, such as appliance substitution, public lighting, and other programmes.

However, it is important to balance this view of the benefits against the many barriers and distortions that can lessen the financial gain and make energy efficiency hard to capture. The cost of capital, taxes and subsidies all matter in determining the attractiveness of an investment, and transaction costs such as programme and administrative costs can significantly reduce the potential savings on offer. In many countries, energy subsidies distort price signals and present a substantial $\mathbf{4 2}^{2}$ McKinsey Global GHG Abatement Cost Curve v2.0

${ }^{43}$ McKinsey, 2009

${ }^{44}$ According to the IPCC, scientific evidence suggests that a scenario where GHG (CO2e) concentrations stabilize at 450ppm gives a 40-60 per cent probability to limit global warming to 2 degrees Celsius.

${ }^{45}$ IEA, 2009

\footnotetext{
${ }^{46}$ Based on the McKinsey Global GHG Abatement Cost Curve v2.0, the energy savings for fuelimporting countries from oil alone of fully capturing this efficiency opportunity would be worth $\$ 180-200$ billion globally in 2030 at a very conservative $\$ 60$ oil price.
} 
47 At present more than $\$ 300$ billion is spent every year in subsidizing carbon-intensive fossil fuels in the 20 largest non-OECD countries. IEA, 2007/ 2008.

${ }^{48}$ International Organization for Standardization (ISO) and UNIDO are jointly working with Member States to promote and support the development of international ISO energy management standards (ISO 50001) for Industry (UNIDO /SAC, 2008).

\footnotetext{
${ }^{49}$ For example, from 1993-2000 Thailand's generating utility, EGAT, invested \$60 million and saved 566MW and

3,140GWh/year. From 2000-04, Brazilian power utilities invested almost \$200 million, which saved $500 \mathrm{MW}$ and 1,500GWh/year (World Bank).
}

disincentive to invest in energy efficiency. ${ }^{47}$ Other major obstacles include capital constraints (in particular for least developed countries), a lack of awareness and understanding of energy efficiency opportunities, the unavailability of energy-efficient technologies, agency issues and split incentives, and the lack of capacity and capabilities in many developing countries to design and implement the required regulations, financing mechanisms and energy efficiency measures.

These barriers can be overcome by a combination of measures, including:

Policy and regulation. Experience shows that changing the behaviour of households, businesses and individuals requires an appropriate regulatory environment, together with direct financial incentives. A broad set of policies is required to set standards, reduce transaction costs, align incentives, monitor performance and otherwise overcome market failures. Changing financial incentives for utilities - to allow them to earn a competitive rate of return on investments in efficiency - is particularly important.

Codes and standards. Energy efficiency standards for lighting and home appliances represent some of the fastest and most easily realized opportunities. In addition, national energy management standards, which have proven successful in OECD countries in delivering significant energy efficiency gains in industry, buildings and transport, can bring worldwide benefits. ${ }^{48}$ But effective tracking and monitoring of implementation of these standards is critical to success. International action on standards can provide momentum by creating the necessary scale to encourage the private sector to invest in research and development to drive down the costs of more efficient technologies.

Financial incentives. Identifying the pricing point of energy at which an efficiency initiative will gain traction is critical. Much work has been done by the World Bank and others to find ways to reduce or phase out subsidies without making poor households worse off. This policy alone would have a dramatic impact on energy use. Other financial incentives may also be required; including access to concessional finance to help overcome cost barriers, or performance-based incentives such as those used in demand-side management programmes. ${ }^{49}$

Access to finance. Given the substantial capital requirements, a critical factor for success is access to finance. To date, a wide range of financing mechanisms has been used around the world, often in conjunction with multilateral financing through the GEF and carbon markets, to enable energy efficiency investments. There are also several examples of successful public-private partnerships providing capital to end-users, such as partnerships with banks.

Institutional capability and capacity development. Delivering the energy efficiency opportunity will require capabilities to be developed across a variety of public and privatesector stakeholders, including policy makers, regulators and enforcement officials, utilities, and implementers. In addition to the United Nations agencies and the World Bank, a number of specialized NGOs funded by private donors have provided critical policy support and capability building for the public sector.

Informational programmes. Education and transparency regarding the benefits of energy efficiency are also important. This is typically achieved through awareness campaigns targeting the private sector and end users, followed by more specific measures such as labeling, upon which consumers can base their decisions.

The most important insight from the various initiatives mentioned above is that achieving energy efficiency improvements on the scale needed will require an integrated approach, with multilateral organizations, governments, utilities, municipalities, industry and the public sector working together and in parallel. Implementing one or two of the success factors is insufficient: a broad, coordinated approach addressing multiple barriers simultaneously is needed to achieve the "critical mass" needed to help convert the enormous untapped energy efficiency potential into real investments across various sectors. Successful initiatives usually require a combination of policy and financial incentive measures enabled through regulation, standards and incentives, as well as innovative financing, institutional and technical capacity building and informational programmes. 


\section{REFERENCES}

Abdullah, S. \& Markandyab, A. 2009. Rural electrification programmes in Kenya: Policy conclusion from a valuation study. University of Bath

aDB (Asian Development Bank). 2005. Republic of the Fiji Islands: Rural Electrification Project. Technical Assistance Consultant's Report

- ASTAE (Asia Sustainable and Alternative Energy Program). 2008. The Last Mile. World Bank Vietnamese Electrification Program Video

- Bajgain, S. \& Shakya, I. 2005. The Nepal Biogas Support Program: A successful model of Private-Public Partnership for Rural Household Energy supply

- Barnes, D. F. 2007. The Challenge of Rural Electrification: Strategies for Developing Countries. ESMAP and RFF (UNDP/World Bank Energy Sector Management Assistance Program and Resources for the Future)

Basnyat, M. B. \& Shrestha, S. K. 2003 Government Policy and Strategies of Improved Cook Stove for Dissemination in Nepal. Alternate Energy Promotion Centre

- Biogas for a Better Life. 2007. Ter Heegte, F. \& Sonder, K. Domestic biogas in Africa: a first assessment of the potential and need; SNV Biogas Practice Team

- ESMAP (UNDP/World Bank Energy Sector Management Assistance Program). 2009. Limaye, D. R., Sarkar, A. \& Singh, J. Large-Scale Residential Energy Efficiency Programmes Based on CFLs: Approaches, Design Issues, and Lessons Learned. World Bank

ESMAP (UNDP/World Bank Energy Sector Management Assistance Program). 2008. Govindarajalu, C., Elahi, R. \& Najendran, J. Electricity Beyond the Grid: Innovative Programmes in Bangladesh and Sri Lanka. ESMAP Knowledge Exchange Series. World Bank

- ESMAP (UNDP/World Bank Energy Sector Management Assistance Program). 2005a. Modi, V. MacDade, S. Lallement, D. \& Saghir, J. Energy Services for the Millennium Development Goals. The Millennium Project. World Bank

- ESMAP (UNDP/World Bank Energy Sector Management Assistance Program). 2005b. Rural Electrification in Tunisia: National Commitment, Efficient Implementation and Sound Finances. World Bank/UNDP joint report

- ESMAP (UNDP/World Bank Energy Sector Management Assistance Program). 2004. Barnes, D. \& Foley, G. Rural Electrification in the Developing World: A summary of lessons from successful programmes. World Bank

- EUEI PDF (European Union Energy Initiative Partnership Dialogue Facility). Strategy on scaling up access to modern energy services in order to achieve the MDGs. GTZ and UNDP Publication

- GEF \& UNEP DTIE (Global Environment Facility and United Nations Environment Programme Division of Technology, Industry and Economics). 2004. MacLean, J. C. \& Siegel, J. M. Financing Mechanisms and Public/Private Risk Sharing Instruments for Financing Small Scale Renewable Energy Equipment and Projects. United Nations Publication

GEF/UN-Energy Report. 2010. Strategic Programme for West Africa - Energy Component. Presented at the Ministerial level Consultations held at Cotonou, Benin. GEF / UN-Energy Report (under publication)

IEA (International Energy Agency). 2010. Niez, A. Comparative study on rural electrification policies in emerging economies - Keys to successful policies. IEA Information Paper 
- IEA (International Energy Agency). 2009. World Energy Outlook 2009. Organization for Economic Cooperation and Development (OECD)/IEA

- IEA (International Energy Agency). 2008a. World Energy Outlook 2008. Organization for Economic Cooperation and Development (OECD)/IEA

- IEA (International Energy Agency). 2008b. Energy Technology Perspectives 2008. Organization for Economic Cooperation and Development (OECD)/IEA

- IEA (International Energy Agency). 2006. World Energy Outlook 2006. Organization for Economic Cooperation and Development (OECD)/IEA

- IEA (International Energy Agency). 2000. World Energy Outlook 2000. Organization for Economic Cooperation and Development (OECD)/IEA

- Informal Working Group on Interim Finance for REDD. 2009. Report of the informal working group on interim finance for REDD+ (IWG-IFR). Discussion document

- Jiahua, P., Wuyuan, P., Meng, L., Xiangyang, W., Zerriffi, H., Elias, B., Zhang, C. \& Victor, D. 2006. Rural Electrification in China 1950-2004: Historical processes and key driving forces. Stanford University Working Paper

- Kenya Environment Donors. 2005. Joint donor statement for the Kenya consultative group meeting energy sector. Consultative Group Meeting

- KPLC (Kenya Power and Lighting Company). 2007. Odhiambo, G. O. Workshop on Rural Electrification presentation

Limmeechokchai and Chawana, 2004. Implication of Biogas Potential in Thailand: The Case Study of Livestock Farm, The Joint International Conference on "Sustainable Energy and Environment (SEE)", 1-3 December 2004, Hua Hin, Thailand

Lucon, O., Coelho, S.T., \& Goldemberg, J. 2004. LPG in Brazil: lessons and challenges. Energy for Sustainable Development, Volume 8 (3)

Madubansi, M. \& Shackleton, C. M. 2006. Changing energy profiles and consumption patterns following electrification in five rural villages, South Africa. Energy Policy, 34 (18): 4081-4092

- Marquard, A., Bekker, B., Eberhard, A. \& Gaunt, T. 2007. South Africa's Electrification Programme - an overview and assessment. Management Programme in Infrastructure Reform and Regulation Graduate School of Business University of Cape Town

- Marsh, R., Larsen, V. G. \& Kragh, M. 2010. Housing and energy in Denmark: past, present and future challenges. Building Research \& Information, 38(1): 92-106.

McKinsey \& Company. 2009. Pathways to a Low-Carbon Economy. Version 2 of the Global Greenhouse Gas Abatement Cost Curve

- McKinsey Global Institute (MGI). 2007. Curbing Global Energy Demand Growth: The Energy Productivity Opportunity. MGI publication

- McKinsey Global Institute (MGI). 2008. Fueling sustainable development: The energy productivity solution. MGI publication

- Practical Action Consulting 2009. Small-Scale Bioenergy Initiatives: Brief description and preliminary lessons on livelihood impacts from case studies in Asia, Latin America and Africa. Prepared for PISCES and FAO by Practical Action Consulting, January 2009

Shrestha, S. K., Thapa, R. \& Bajracharya, K. 2003. National Improved Cook Stove Dissemination in the Mid-Hills of Nepal: Experiences, Opportunities and Lesson learnt; Asia Regional Cook Stove Programme.

Southwest Windpower. Wind Power Improves Islanders' Quality of Life. Sri Lanka case study 
Stephen, R. \& Sokopo, I. 2006. Eskom Rural Electrification Experience - Lessons Learnt. Eskom presentation to UPDEA

UNDP (United Nations Development Programme). 2008. Watkins, K. Human Development Report - Fighting Climate Change: Human Solidarity in a Divided World, $2007 / 8$

UNDP \& WHO (United Nations Development Programme and World Health Organization). 2009. The Energy Access Situation in Developing Countries - A review focusing on least developed countries and SSA. Sustainable Energy Programme Environment and Energy Group Report

UN-Energy. 2009. Policies and Measures to Realize Industrial Energy Efficiency and Mitigate Climate Change.

UNIDO. 2005. Motor system energy conservation programme (China). Final report. Vienna.

UNIDO/Standards Administration of China. 2008. Towards an international energy management standard. Final report. Vienna/Beijing.

- UNIDO/Africa Union Report 2008. Scaling up Renewable Energy in Africa: Action Plan adopted by the International Conference on Renewable energy in Africa, April 2008, Dakar, Senegal

Venkataramanan, G. \& Marnay, C. 2008. A large role for microgrids - are microgrids a viable paradigm for electricity supply expansion. IEEE power and energy magazine

- Vipradas, M. C. Sri Lanka Off Grid Electrification. REEEP (Renewable Energy and Energy Efficiency Partnership)

- World Bank. 2009a. Hung, V. T. Vietnam Rural Electrification Program. World Bank presentation in Mozambique

- World Bank. 2009b. Africa's infrastructure, a time for transformation. World Bank Africa Infrastructure Country Diagnostic

- World Bank. 2009c. Climate Change and the World Bank Group - Phase I: An Evaluation of World Bank Win-Win Energy Policy Reforms. World Bank and IEG (Independent Evaluation Group) Report

- World Bank. 2008a. Sarkar, A. Large Scale CFL Deployment Programs: Mainstreaming Carbon Finance and CDM. Phase Out 2008 presentation

- World Bank. 2008b. Costing Power Infrastructure Investment Needs in Southern and Eastern Africa. Econ Pöyry Report

- World Bank. 2008c. Rosnes, O. \& Vennemo, H. Africa Infrastructure Country Diagnostic - Powering Up: Costing Power Infrastructure Investment Needs in Southern and Eastern Africa. Econ Pöyry Report

World Bank. 2005. Komives, K. Foster, V. Halpern, J. \& Wodon, Q. Water, Electricity and the Poor: Who benefits from utility subsidies? The International Bank for Reconstruction and Development/World Bank

World Bank. 2001. West Africa LPG Market Development Study. World Bank and World LP Gas Association

- World Bank/IDA (International Development Association). 2000. Vietnam Rural Energy Project Information. World Bank Projects and Operations Database

- World Bank. Undated. China: Implementing Building Energy Efficiency Codes. World Bank Note 
